\title{
Austria quits CERN after 50 years
}

Austria has announced that it will withdraw from CERN, Europe's premier high-energy physics laboratory, located near Geneva in Switzerland. The announcement - just months before the restart of the Large Hadron Collider (LHC), the world's most powerful particle accelerator - has left Austrian physicists stunned.

"It is a black day for Austrian science," says Christian Fabjan, who heads the Institute for High Energy Physics at the Austrian Academy of Sciences in Vienna. Fabjan says that he was "totally shocked" by the announcement, which was made on 8 May by Johannes Hahn, the science minister and a member of the conservative Austrian People's Party (ÖVP).

Only two other nations have withdrawn from CERN in its 55-year history: Yugoslavia pulled out of the lab in 1961, and Spain left in 1969, only to rejoin in 1983.

Austria joined CERN in 1959, one of the first nations to do so. Two of the laboratory's directors, Willibald Jentschke and Victor Frederick
Weisskopf, have been Austrian-born, and the country has 170 scientists working on the LHC and its two largest experiments, ATLAS and the compact muon solenoid. Under the terms of the withdrawal, Austria's participation would end in 2010.

"Nobody is happy about the decision. We would have loved to stay in CERN," says Nikola Donig, a spokesman for the Austrian ministry of science. But, he adds, "budgets are tight". Austria's budget, completed this April, actually increases funding for science,

\section{"Nobody is happy} about the decision."
Among those are the European Biobanking and Biomolecular Research Resources Infrastructure project, the European X-ray Free Electron Laser near Hamburg, Germany, and the Facility for Antiproton and Ion Research in Darmstadt, Germany.

Donig says the decision is about getting the greatest return for the government's money. "We want to fund fields where we can have more impact for businesses and universities," he says.

On 11 May, Rolf-Dieter Heuer, CERN's director-genhe says. But private funding for basic research has dropped off drastically since the start of the economic downturn.

The government will use its contribution to CERN - roughly $€ 17$ million (US\$23 million) per year, or $2 \%$ of the laboratory's budget - to make up some of that shortfall and to begin participation in other international collaborations in physics, sociology and biotechnology. eral, held what he described as a "constructive" meeting with Hahn. "I think we can still negotiate," Heuer says. He hopes that officials from CERN and the Austrian government can meet in the coming weeks to discuss ways to continue the nation's participation.

The decision still has to be approved by AusGeoff Brumfiel tria's government, parliament and president. 